\title{
FAKTOR-FAKTOR YANG BERHUBUNGAN DENGAN PERDARAHAN POST PARTUM PADA IBU BERSALIN DI RSUD PRINGSEWU TAHUN 2016
}

\section{INFO ARTIKEL}

Riwayat Artikel:

Diterima: 11-01-2018

Disetujui: 30-01-2018

\section{Kata Kunci:}

Atonia Uteri, Laserasi Jalan Lahir Perdarahan, Retensio Plasenta

\author{
$\underline{\text { Heni Anggraini }{ }^{1}, \underline{\text { Dewi Riansari }}{ }^{2}}$ \\ Kebidanan, STIKes Aisyah, Bandar Lampung, 35131, Indonesia \\ anggraini.1506@yahoo.com
}




\section{A. LATAR BELAKANG}

Kematian ibu adalah kematian seorang wanita terjadi saat hamil, bersalin atau 42 hari setelah persalinan dengan penyebab yang berhubungan langsung atau tidak langsung terhadap persalinan.World Health Organization (WHO) memperkirakan 800 perempuan meninggal setiap harinya akibat komplikasi kehamilan dan proses kelahiran. Sekitar 99\% dari seluruh kematian ibu terjadi di Negara berkembang.Sekitar 80\% kematian maternal merupakan akibat meningkatnya komplikasi selama kehamilan, persalinan dan setelah persalinan (WHO, 2014).

Kementerian Kesehatan Republik Indonesia menilai angka kematian ibu melahirkan di Indonesia relatif tinggi. Berdasarkan hasil Survey Demografi Kesehatan Indonesia (SDKI) menunjukkan bahwa secara nasional Angka Kematian Ibu pada tahun 2012 di Indonesia adalah 359/100.00o kelahiran hidup. Rata-rata kematian ini jauh melonjak dibanding hasil SDKI 2007 yang mencapai 228/ 100.000 kelahiran hidup (Kemenkes RI, 2013).

Menurut Profil Kesehatan Indonesia tahun 2014 empat penyebab kematian ibu terbesar yaitu perdarahan 30,3\%, hipertensi dalam kehamilan (HDK) $27,1 \%$, infeksi $7,3 \%$, dan lain-lain yaitu penyebab kematian ibu tidak langsung seperti kondisi penyakit kanker, ginjal, jantung atau penyakit lain yang diderita ibu sebesar 35,3\% (Kemenkes RI, 2014).

Faktor penyebab kematian ibu melahirkan secara langsung adalah perdarahan yang disebabkan oleh Antonia uteri dan penyebab tidak langsung adalah usia yang beresiko dan paritas (Manuaba, 2009).

Tujuan terselengaranya pembangunan kesehatan untuk meningkatkan status kesehatan masyarakat lampung diharapkan akan tercapai akhir tahun 2019 yaitu Angka Kematian Ibu (AKI) per 100.000 kelahiran hidup diharapkan akan tercapai menjadi 149 per 100.0oo kelahiran hidup, Angka Kematian Bayi (AKB) per 1000 kelahiran hidup diharapkan akan tercapai menjadi 25 per 1000 kelahiran hidup (Profil Dinas Kesehatan Provinsi Lampung Tahun 2015).

Berdasarkan data yang diperoleh peneliti pada di Ruang Kebidanan RSUD Kabupaten Pringsewu. Jumlah ibu bersalin pada tahun 2014 sebesar 530 ibu yang melakukan persalinan normal, pada tahun 2015 didapatkan $590 \mathrm{ibu}$ yang melakukan persalinan normal. Sedangkan di tahun 2016 terdapat $498 \mathrm{ibu}$ yang melakukan persalinan normal dan yang mengalami perdarahan sebanyak 19 ibu post partum.

\section{B. METODE PENELITIAN}

Penelitian ini dilakukan Juli 2017 periode Januari sampai dengan Desember 2016.Tempat penelitian adalah RSUD Pringsewu tahun 2017.

Penelitian ini menggunakan rancangan penelitian analitik yaitu penelitian yang mencoba menggali bagaimana dan mengapa fenomena itu terjadi (Notoatmodjo, 2010).

Dalam penelitian ini menggunakan pendekatan crossectional.Teknik pengambilan sampel yang digunakan dalam penelitian ini adalah random sampling, dengan membagi jumlah atau anggota populasi dengan jumlah sampel yang di inginkan, hasilnya adalah interval sampel (Notoatmodjo, 2012).Jumlah sampel sebanyak 222 responden, pengambilan sampel dengan random sampling interval 1 responden.

\section{HASIL}

\section{Post Partum}

TABEL 1

Distribusi Frekuensi Perdarahan Post Partum di RSUD Pringsewu Tahun 2016

\begin{tabular}{|c|l|c|c|}
\hline No & $\begin{array}{c}\text { Perdarahan Post } \\
\text { Partum }\end{array}$ & $\begin{array}{c}\text { Frekuensi } \\
\text { (n) }\end{array}$ & $\begin{array}{c}\text { Persentase } \\
\text { (\%) }\end{array}$ \\
\hline 1 & Perdarahan & 17 & 7,7 \\
\hline 2 & Tidak Perdarahan & 205 & 92,3 \\
\hline \multicolumn{2}{|c|}{ Jumlah } & 222 & 100 \\
\hline
\end{tabular}

Berdasarkan analisa Univariat pada Tabel 1 distribusi frekuensi perdarahan post partum, didapatkan sebagian besar tidak perdarahan yaitu sebanyak 205 responden (92,3\%), dan yang terjadi perdarahan sebanyak 17 responden $(7,7 \%)$.

\section{Atonia Uteri}

\section{TABEL 2}

Distribusi frekuensi Atonia Uteri dengan Perdarahan Post Partum di RSUD Pringsewu Tahun 2016

\begin{tabular}{|l|l|c|c|}
\hline No & Atonia Uteri & $\begin{array}{c}\text { Frekuen } \\
\text { si (n) }\end{array}$ & $\begin{array}{c}\text { Persentase } \\
\text { (\%) }\end{array}$ \\
\hline $\mathbf{1}$ & Atonia Uteri & 13 & 5,9 \\
\hline $\mathbf{2}$ & Tidak Atonia Uteri & 209 & 94,1 \\
\hline \multicolumn{2}{|c|}{ Jumlah } & 222 & 100 \\
\hline
\end{tabular}

Berdasarkan analisa Univariat pada Tabel 2 distribusi frekuensi atonia uteri, dari jumlah sampel 222 responden didapatkan sebagian besar tidak atonia uteri 209 responden (94,1\%), dan atonia uteri sebanyak 13 responden $(5,9 \%)$. 


\section{Retensio Plasenta}

TABEL 3

Distribusi frekuensi Retensio Plasenta dengan Perdarahan Post Partum di RSUD Pringsewu Tahun 2016

\begin{tabular}{|c|l|c|c|}
\hline No & $\begin{array}{l}\text { Retensio } \\
\text { Plasenta }\end{array}$ & $\begin{array}{c}\text { Frekuensi } \\
\text { (n) }\end{array}$ & $\begin{array}{c}\text { Persentase } \\
\text { (\%) }\end{array}$ \\
\hline 1. & $\begin{array}{l}\text { Retensio } \\
\text { plasenta }\end{array}$ & 18 & 8,1 \\
\hline 2. & $\begin{array}{l}\text { Tidak Retensio } \\
\text { Plasenta }\end{array}$ & 204 & 91,9 \\
\hline \multicolumn{2}{|r|}{ Jumlah } & $\mathbf{2 2 2}$ & $\mathbf{1 0 0}$ \\
\hline
\end{tabular}

Berdasarkan analisa Univariat pada Tabel 4.3 distribusi frekuensi Retensio plasenta, didapatkan sebagian besar tidak retensio plasenta yaitu 204 responden $(91,9 \%)$,dan yang mengalami retensio plasenta yaitu sebanyak 18 responden $(8,1 \%)$.

\section{Laserasi Jalan Lahir}

Tabel 4

Distribusi frekuensi Laserasi Jalan Lahir dengan Perdarahan Post Partum di RSUD Pringsewu

Tahun 2016

\begin{tabular}{|l|l|c|c|}
\hline No & $\begin{array}{l}\text { Laserasi } \\
\text { jalan lahir }\end{array}$ & $\begin{array}{c}\text { Frekuensi } \\
\text { (n) }\end{array}$ & $\begin{array}{c}\text { Presentase } \\
\text { (\%) }\end{array}$ \\
\hline 1. & Laserasi & 63 & 28,3 \\
\hline 2. & $\begin{array}{l}\text { Tidak } \\
\text { laserasi }\end{array}$ & 159 & 71,7 \\
\hline \multicolumn{2}{|c|}{ Jumlah } & $\mathbf{2 2 2}$ & $\mathbf{1 0 0}$ \\
\hline
\end{tabular}

Berdasarkan analisa Univariat pada Tabel 4.4 distribusi frekuensi laserasi jalan lahir, dari jumlah 222 responden didapatkan sebagian besar tidak laserasi yaitu sebanyak 159 responden $(71,7 \%)$, dan yang terjadi laserasi yaitu sebanyak 63 responden $(28,3 \%)$.

5. Hubungan Atonia Uteri dengan Perdarahan Post Partum di RSUD Pringsewu Tahun 2016

TABEL 5

Hubungan Atonia Uteri dengan Perdarahan Post Partum di RSUD Pringsewu Tahun 2016

\begin{tabular}{|c|c|c|c|c|c|c|c|c|}
\hline \multirow{3}{*}{ Atonia Uteri } & \multicolumn{4}{|c|}{ Perdarahan Post Partum } & \multirow{2}{*}{\multicolumn{2}{|c|}{ Jumlah }} & \multirow{3}{*}{ P-Value } & \multirow{3}{*}{ OR (95\%-CI) } \\
\hline & \multicolumn{2}{|c|}{ Perdarahan } & \multicolumn{2}{|c|}{$\begin{array}{c}\text { Tidak } \\
\text { Perdarahan }\end{array}$} & & & & \\
\hline & $\mathbf{n}$ & $\%$ & $\mathbf{n}$ & $\%$ & $\mathbf{n}$ & $\%$ & & \\
\hline Atonia Uteri & 4 & 30,8 & 9 & 69,2 & 13 & 100 & \multirow{3}{*}{0,009} & \multirow{3}{*}{$\begin{array}{c}7,296(1,961- \\
27,152)\end{array}$} \\
\hline Tidak Atonia Uteri & 12 & 5,7 & 197 & 94,3 & 209 & 100 & & \\
\hline Jumlah & 16 & 7,2 & 206 & 92,8 & 222 & 100 & & \\
\hline
\end{tabular}

\section{Hubungan Retensio Plasenta dengan Perdarahan Post Partum di RSUD Pringsewu}

TABEL 6

Hubungan Retensio Plasenta dengan Perdarahan Post Partum di RSUD Pringsewu Tahun 2016

\begin{tabular}{|c|c|c|c|c|c|c|c|c|}
\hline \multirow{3}{*}{$\begin{array}{l}\text { Laserasi } \\
\text { Jalan Lahir }\end{array}$} & \multicolumn{4}{|c|}{ Perdarahan } & \multirow{2}{*}{\multicolumn{2}{|c|}{ Jumlah }} & \multirow{3}{*}{$\begin{array}{c}\text { P- } \\
\text { Value }\end{array}$} & \multirow{3}{*}{ OR (95\%-CI) } \\
\hline & \multicolumn{2}{|c|}{ Perdarahan } & \multicolumn{2}{|c|}{$\begin{array}{c}\text { Tidak } \\
\text { Perdarahan }\end{array}$} & & & & \\
\hline & $\mathbf{n}$ & $\%$ & $\mathbf{n}$ & $\%$ & $\mathbf{n}$ & $\%$ & & \\
\hline Laserasi & 12 & 19 & 51 & 81 & 63 & 100 & \multirow{3}{*}{0,000} & \multirow{3}{*}{$\begin{array}{c}9,118(2,816- \\
29,524)\end{array}$} \\
\hline Tidak laserasi & 4 & 2,5 & 155 & 97,5 & 159 & 100 & & \\
\hline Jumlah & 16 & 7,2 & 206 & 92,8 & 222 & 100 & & \\
\hline
\end{tabular}

7. Hubungan Laserasi Jalan Lahir dengan Perdarahan Post Partum di RSUD Pringsewu Tahun 2016

Tabel 7

Hubungan Laserasi Jalan Lahir dengan Perdarahan Post Partum di RSUD Pringsewu Tahun 2016

\begin{tabular}{|c|c|c|c|c|c|c|c|c|}
\hline \multirow{3}{*}{ Retensio Plasenta } & \multicolumn{4}{|c|}{ Perdarahan } & \multirow{2}{*}{\multicolumn{2}{|c|}{ Jumlah }} & \multirow{3}{*}{$\begin{array}{c}\text { P- } \\
\text { Value }\end{array}$} & \multirow{3}{*}{ OR (95\%-CI) } \\
\hline & \multicolumn{2}{|c|}{ Perdarahan } & \multicolumn{2}{|c|}{$\begin{array}{c}\text { Tidak } \\
\text { Perdarahan } \\
\end{array}$} & & & & \\
\hline & $\mathbf{n}$ & $\%$ & $\mathbf{n}$ & $\%$ & $\mathbf{n}$ & $\%$ & & \\
\hline Retensio Pasenta & 7 & 38,9 & 11 & 61,1 & 18 & 100 & \multirow{3}{*}{0,000} & \multirow{3}{*}{$\begin{array}{c}13,788(4,324- \\
43,962)\end{array}$} \\
\hline $\begin{array}{l}\text { Tidak Retensio } \\
\text { Plasenta }\end{array}$ & 9 & 4,4 & 195 & 95,6 & 204 & 100 & & \\
\hline Jumlah & 16 & 7,2 & 206 & 92,8 & 222 & 100 & & \\
\hline
\end{tabular}




\section{PEMBahasan}

\section{Perdarahan Post Partum}

Berdasarkan hasi analisa Univariat pada Tabel 1 distribusi frekuensi perdarahan post partum, dari jumlah sampel 222 responden didapatkan sebagian besar tidak perdarahan yaitu sebanyak 205 responden $(92,3 \%)$, dan yang terjadi perdarahan sebanyak 17 responden $(7,7 \%)$.

Perdarahan post partum adalah perdarahan lebih dari 500-600 ml selama 24 jam setelah anak lahir termasuk perdarahan karena retensio plasenta. Perdarahan post partum adalah perdarahan dalam kala IV lebih dari 500-600 cc dalam 24 jam setelah anak dan plasenta lahir (Mochtar, 2008).

Penelitian ini didukung oleh penelitian Hanifah, dkk. Hubungan Pelaksanaan Manajemen Aktif Kala Tiga dengan Penurunan Kejadian Perdarahan Pasca Persalinan Pada Ibu Bersalin di BPS Ny. S Kecamatan Pakis Kabupaten Malang.

Menurut peneliti dari hasil penelitian yang telah dilakukan didapatkan hasil sebagian responden yang mengalami perdarahan lebih sedikit dibandingkan dengan yang tidak mengalami perdarahan.Hal ini dikarenakan faktor penyebab terjadinya perdarahan seperti atonia uteri, retensio plasenta dan laserasi jalan lahir telah mengalami penurunan. Usia, paritas, dan jarak kehamilan, anemia juga faktor penyebab terjadinya perdarahan. Terlalu muda, dan terlalu tua, terlalu dekat proses persalinan dapat menyebabkan terjadinya perdarahan post partum, makadari itu disarankan agar selama kehamilan ibu melakukan kunjungan Antenatal Care (ANC) untuk mencegah terjadinya komplikasi selama kehamilan, persalinan dan nifas.

\section{Atonia Uteri dengan Perdarahan Post Partum}

Berdasarkan hasil analisa Univariat pada Tabel 2 distribusi frekuensi dari jumlah sampel 222 responden didapatkan sebagian besar tidak atonia uteri 209 responden $(94,1 \%)$, dan atonia uteri sebanyak 13 responden (5,9\%).

Perdarahan post partum dapat terjadi karena terlepasnya sebagian plasenta dari rahim dan sebagian lagi belum, karena perlukaan pada jalan lahir atau karena atonia uteri. Atonia uteri merupakan sebab terpenting perdarahan post partum (Wiknjosastro, 2010).

Penelitian ini didukung oleh penelitian Eniyati, dkk (2014). Analisa Penyebab - Penyebab Primer Kejadian Perdarahan Post Partum pada Ibu Bersalin di Kecamatan Dente Teladas Kabupaten Tulang Bawang Provinsi Lampung.

Menurut peneliti dari hasil penelitian yang telah dilakukan didapatkan hasil sebagian responden yang mengalami atonia uteri lebih sedikit dibandingkan yang tidak mengalami atonia uteri dan ini sangat baik, karena jika lebih banyak yang mengalami atonia uteri maka akan lebih banyak yang mengalami perdarahan sehingga Angka Kesakitan dan Kematian Ibu di Indonesia khususnya Pringsewu meningkat.

\section{Retensio Plasenta dengan Perdarahan Post Partum}

Berdasarkan hasil analisa Univariat pada Tabel 3 distribusi frekuensi Retensio plasenta, dari jumlah sampel 222 responden didapatkan sebagian besar tidak retensio plasenta yaitu 204 responden (91,9\%),dan yang mengalami retensio plasenta yaitu sebanyak 18 responden (8,1\%). Retensio plasenta adalah plasenta yang belum lahir setengah jam sesudah bayi lahir (Wiknjosastro, 2010). Penelitian ini didukung oleh penelitian Friyandini, dkk (2013).Hubungan Kejadian Perdarahan Postpartum dengan Faktor Resiko Karakteristik Ibu di RSUP Dr. M. DJamil Padang pada Januari 2012April 2013.

Menurut peneliti sebagian besar responden dalam penelitian ini adalah ibu bersalin dengan terjadi retensio plasenta lebih sedikit dibandingkan dengan yang tidak terjadi retensio plasenta. Jika setiap tahun kejadian retensio plasenta mengalami penurunan, maka Angka Kematian dan kesakitan Ibu khususnya di Pringsewu akan mengalami penurunan. Usia dan paritas pada ibu bersalin juga merupakan salah satu dari beberapa faktor yang menyebabkan kejadian retensio plasenta, maka untuk ibu yang terlalu tua dan terlalu muda, dan ibu yang telah banyak anak disarankan untuk pemasangan alat kontrasepsi

\section{Laserasi Jalan Lahir dengan Perdarahan Post Partum}

Berdasarkan hasil analisa Univariat pada Tabel 4 distribusi frekuensi laserasi jalan lahir dari jumlah 222 responden didapatkan sebagian besar tidak laserasi yaitu sebanyak 159 responden $(71,7 \%)$, dan yang terjadi laserasi yaitu sebanyak 63 responden $(28,3 \%)$ dan didapatkan $\mathrm{OR}=9,118$ $(2,816-29,524)$.

Robekan jalan lahir merupakan penyebab kedua tersering dari perdarahan post partum. Robekan dapat terjadi bersamaan dengan atonia uteri.perdarahan post partum dengan uterus yang berkontraksi baik biasanya disebabkan oleh robekan servik atau vagina (Wiknjosastro, 2010).

Penelitian ini didukung oleh penelitian Hanifah, dkk. Hubungan Pelaksanaan Manajemen Aktif Kala Tiga dengan Penurunan Kejadian Perdarahan Pasca Persalinan Pada Ibu Bersalin di BPS Ny. S Kecamatan Pakis Kabupaten Malang.

Menurut peneliti sebagian besar hasil penelitian didapatkan responden post partum yang tidak terjadi laserasi jalan lahir lebih besar dibandingkan dengan yang terjadi laserasi. Jika responden pada proses persalinan terjadi laserasi maka dapat terjadi perdarahan post partum. Laserasi dapat 
disebabkan oleh beberapa faktor yaitu bayi yang terlalu besar, persalinan dengan tindakan, ekstraksi vakum, ekstraksi cunam, persalinan dengan riwayat bekas secsio sesaria dan lain-lain. Dan jika pada proses persalinan ibu melakukan proses persalinan dengan benar, bayi yang dilahirkan tidak lebih dari 4000 gram, dan perineum elastis, laserasi tidak terjadi. Ibu sangat berperan dalam terjadinya laserasi jalan lahir. Maka dari itu diharapkan pada seluruh ibu yang akan bersalin untuk mengikuti anjuran yang diberikan oleh petugas kesehatan (bidan) agar dapat meneran dengan baik sehingga tidak terjadi laserasi pada jalan lahir dan menurunkan angka kesakitan dan kematian akibat perdarahan laserasi jalan lahir.

\section{Hubungan Atonia Uteri dengan Perdarahan Post Partum}

Berdasarkan hasil analisa Bivariat pada tabel 5 diatas, dapat dijelaskan bahwa P-Value $=0,009<$ o,05 maka dapat disimpulkan bahwa Ha diterima ada hubungan antara Atonia uteri dengan perdarahan poss partum di RSUD Pringsewu Tahun 2016. Dan didapatkan OR=7,296 (1,96127,152).

Atonia uteri merupakan sebab terpenting perdarahan post partum. Atonia uteri dapat terjadi karena proses persalinan yang lama, perdarahan rahim yang berlebihan pada waktu hamil seperti pada hamil kembar atau janin besar, persalinan yang sering dijumpai (multiparitas) atau anestesi yang dalam.

Penelitian ini didukung oleh penelitian Eniyati, dkk (2014). Analisa Penyebab - Penyebab Primer Kejadian Perdarahan Post Partum pada Ibu Bersalin di Kecamatan Dente Teladas Kabupaten Tulang Bawang Provinsi Lampung.

Menurut peneliti sebagian besar responden dalam penelitian ini yang mengalami atonia uteri lebih sedikit dibandingkan dengan yang tidak mengalami atonia uteri, maka jika setiap tahun Angka Kematian Ibu (AKI) akibat perdarahan, dan atonia uteri menurun dapat membantu target penurunan Angka Kematian Ibu (AKI) di tahuntahun selanjutnya. Akan lebih baik jika ibu dalam proses kehamilan tidak terlalu tua dan terlalu muda, karena usia sangat berpengaruh dalam persalinan, dan usia adalah salah satu faktor penyebab dari atonia uteri.

\section{Hubungan Retensio Plasenta dengan Perdarahan Post Partum}

Berdasarkan hasil analisa Bivariat pada tabel 6 diatas, dapat dijelaskan bahwa P-Value $=0,000<$ 0,05 maka dapat disimpulkan bahwa Ha diterima ada hubungan retensio plasenta dengan perdarahan post partum di RSUD Pringsewu Tahun 2016 didapatkan $\mathrm{OR}=13,788(4,324-43,962)$.
Retensio plasenta adalah plasenta yang belum lahir setengah jam sesudah bayi lahir (Wiknjosastro, 2010).

Penelitian ini didukung oleh penelitian Friyandini, dkk (2013).Hubungan Kejadian Perdarahan Postpartum dengan Faktor Resiko Karakteristik Ibu di RSUP Dr. M. DJamil Padang pada Januari 2012-April 2013.

Menurut peneliti sebagian besar responden dalam penelitian ini lebih banyak yang tidak terjadi retensio plasenta dibandingkan dengan yang terjadi retensio plasenta, ini dikarenakan beberapa faktor yang terjadi dalam proses persalinan seperti his yang baik dan plasenta yang lahir kurang dari 30 menit, dan jika his baik dan plasenta lahir kurang dari 30 menit maka perdarahan post partum akibat retensio dapat mengurangi angka kesakitan dan kematian ibu post partum. Selain itu usia yang terlalu muda dan terlalu tua, dan yang terlalu banyak melakukan persalinan juga pemicu terjadinya retensio plasenta.

\section{Hubungan Laserasi Jalan Lahir dengan Perdarahan Post Partum}

Berdasarkan hasil analisa Bivariat pada tabel 7 diatas, dapat dijelaskan bahwa P-Value $=0,000<$ 0,05 maka dapat disimpulkan bahwa Ha diterima ada hubungan antara laserasi jalan lahir dengan perdarahan post partum di RSUD Pringsewu Tahun 2016 dan didapatkan $\mathrm{OR}=9,118(2,816-29,524)$.

Perdarahan yang cukup banyak dapat terjadi dan robekan yang dialami selama proses melahirkan baik yang normal ataupun dengan tindakan. Jalan lahir harus diinspeksi sesudah tiap kelahiran selesai sehingga sumber perdarahan bisa dikendalikan.

Penelitian ini didukung oleh penelitian Hanifah, dkk. Hubungan Pelaksanaan Manajemen Aktif Kala Tiga dengan Penurunan Kejadian Perdarahan Pasca Persalinan Pada Ibu Bersalin di BPS Ny. S Kecamatan Pakis Kabupaten Malang.

Menurut peneliti sebagian besar responden dalam penelitian ini yang pada proses persalinan tidak terjadi laserasi lebih banyak dibandingkan dengan yang mengalami laserasi jalan lahir. Banyak faktor yang mendukung dalam proses yang dapat menyebabkan laserasi jalan lahir yaitu meneran yang salah, his yang kuat dan lain-lain, maka dari itu sebaiknya pada proses persalinan ibu harus bekerja sama dengan tenaga kesehatan untuk mengikuti anjuran yang diberikan. Jika responden mengerti cara meneran yang baik, dan bayi tidak terlalu besar maka tidak terjadi laserasi jalan lahir.

\section{E. SIMPULAN}

Dari hasil penelitian yang dilakukan maka dapat disimpulkan bahwa :

1. Distribusi frekuensi perdarahan post partum di RSUD Pringsewu tahun 2016, yaitu responden 
yang tidak terjadi perdarahan sebanyak 205 responden (92,3\%), dan yang terjadi perdarahan sebanyak 17 responden $(7,7 \%)$.

2. Distribusi frekuensi antara atonia uteri dengan perdarahan post partum di RSUD Pringsewu tahun 2016, yaitu didapatkan sebagian besar tidak atonia uteri 209 responden $(94,1 \%)$, dan atonia uteri sebanyak 13 responden $(5,9 \%)$.

3. Distribusi frekuensi antara retensio plasenta dengan perdarahan post partum di RSUD Pringsewu tahun 2016, yaitu didapatkan sebagian besar tidak retensio plasenta yaitu 204 responden (91,9\%),dan yang mengalami retensio plasenta yaitu sebanyak 18 responden $(8,1 \%)$.

4. Distribusi frekuensi antara laserasi dengan perdarahan post partum di RSUD Pringsewu tahun 2016, yaitu didapatkan sebagian besar tidak laserasi yaitu sebanyak 159 responden $(71,7 \%)$, dan yang terjadi laserasi yaitu sebanyak 63 responden $(28,3 \%)$.

5. Ada hubungan antara atonia uteri dengan perdarahan post partum di RSUD Pringsewu tahun 2016, yaitu P-Value $=0,009<0,05$, $\mathrm{OR}=7,296(1,961-27,152)$.

6. Ada hubungan antara retensio plasenta dengan perdarahan post partum di RSUD Pringsewu tahun 2016, P-Value $=0,000<0,05 \mathrm{OR}=13,788$ (4,324-43,962).

7. Ada hubungan antara laserasi jalan lahir dengan perdarahan post partum di RSUD Pringsewu tahun 2016, P-Value $=0,000<0,05 \mathrm{OR}=9,118$ $(2,816-29,524)$.

\section{DAFTAR PUSTAKA}

Arikunto, 2006. Prosedur Penelitian Suatu Pendekatan Praktik.Jakarta: PT. Rineka Cipta.

Departemen Kesehatan RI, (2011). Pedoman Pelayanan Antenatal. Jakarta: Dirjen Binkesmas Depked RI.

Eniyati, dkk. 2014. Analisa Penyebab - Penyebab Primer Kejadian Perdarahan Post Partum Pada Ibu Bersalin di Kecamatan Dente Teladas Kabupaten Tulang Bawang Provinsi Lampung. Fakultas Keseehatan Masyarakat Unmal Bandar Lampung

Friyandini, dkk. 2013. Hubungan Kejadian Perdarahan Postpartum dengan Faktor Resiko Karakteristik Ibu di RSUP Dr. Djamil Padang pada Januari 2012 - April 2013.

Hanifah, dkk. Hubungan Pelaksanaan Manajemen Kala Tiga dengan PenurunanKejaduan Perdarahan Pascasalin pada Ibu Bersalin di BPS Ny. "S" Kecamatan Pakis Kabupaten Malang. Sekolah Tinggi Ilmu Kesehatan Kendedes.

Hastono, 2007.Analisa Data Kesehatan. Jakarta: FKM.UI.
Manuaba, 2007.Ilmu Kebidanan. Jakarta: EGC.

Notoatmodjo, Soekidjo. 2010. Metodologi Penelitian Kesehatan. Jakarta: Rineka Cipta.

Profil Dinas Kesehatan Indonesia, 2014.http://www.depkes.go.id/resources/do wnload/pusdatin

Profil Dinas Kesehatan Provinsi Lampung, 2014. http://www.depkes.go.id/resources/downloa d

Rukiyah, A. Y, dkk.(2009). Asuhan Kebidanan II (Persalinan). Jakarta: CV. Trans Info.

Sarwono, 2008.Ilmu Kandungan. Jakarta: Yayasan bina pustaka

Sugiyno, 2007. Metode Penelitian Kuantitatif, Kuakitatif dan R \& D. Bandung: Alfabeta

Sulistyawati, Ari. 2010. Buku Ajar Asuhan Kebidanan Pada Ibu Bersalin. Jakarta: Salemba Medika.

Sumarah, dkk. 2009. Perawatan Ibu Bersalin (Asuhan Kebidanan Pada Ibu Bersalin). Jakarta: Fitramaya.

Varney, 2008. Buku Ajar Asuhan Kebidanan Edisi I. Jakarta: EGC. Wiknjosastro, H. 2010. Ilmu Kebidanan. Jakarta: Yayasan bina pustaka 